\title{
Composição Químico-Bromatológica e Degradabilidade In Situ da Matéria Seca, Proteína Bruta e Fibra em Detergente Neutro da Casca do Fruto de Três Variedades de Maracujá (Passiflora spp) ${ }^{1}$
}

\author{
Cláudio Villela Vieira ${ }^{2}$, Hernan Maldonado Vasquez ${ }^{3}$, José Fernando Coelho da Silva ${ }^{4}$
}

\begin{abstract}
RESUMO - O objetivo deste trabalho foi avaliar a composição químico-bromatológica e as degradabilidades potenciais e efetivas da matéria seca (MS), proteína bruta (PB) e fibra em detergente neutro (FDN) do resíduo (casca) das variedades de maracujá amarela (Passiflora edulis f. Flavicarpa Degener), roxa (Passiflora edulis Sims) e doce (Passiflora alata) e da mistura das variedades amarela e roxa. Calcularam-se, também, o consumo de MS e as concentrações de amônia, ácidos graxos voláteis e pH no líquido ruminal e a taxa de passagem das fases líquida e sólida da digesta no rúmen de bovinos. Os resíduos (casca) in natura apresentaram grande quantidade de água, enquanto a variedade roxa apresentou o maior teor de matéria seca (17,01\%) e o amarelo, o menor (10,78\%). O teor de proteína bruta variou de $9,82 \%$ na MS, para a variedade amarela, a 7,53\%, para a doce. O teor de fósforo foi 0,13\% na MS para a variedade doce, chegando a 0,09 , para a roxo, e $0,08 \%$, para a amarelo. Os teores de cálcio, FDN e FDA não diferiram entre as variedades. Às 48 horas de incubação no rúmen, a degradabilidade atingiu ponto máximo para o teor de MS, PB e FDN. Houve interação de tempo e variedade na degradabilidade de MS, PB e FDN. As degradabilidades de PB e FDN foram influenciadas pelas variedades. A DE da FDN foi maior para a mistura (45,85\%) e menor para a doce $(34,61 \%)$. O consumo médio de MS foi de $16,90 \mathrm{~kg} / \mathrm{animal}$, equivalente a $3,27 \%$ do peso vivo ou $156,11 \mathrm{~g} / \mathrm{kg}^{0,75}$, quando se utilizou farelo de casca (resíduo) com 90\% de MS. As concentrações de ácidos graxos voláteis mantiveram-se na faixa de 7,76 a 10,87 mmoles/ $100 \mathrm{~mL}$. O pH do líquido ruminal variou de 6,03 a 6,75 e o $\mathrm{N}$-amoniacal, de 4,93 a 9,86 mg/100 mL.
\end{abstract}

Palavras-chave: composição química, degradabilidade, maracujá, parâmetro ruminal

\section{Chemical Composition and In Situ Degradability of Dry Matter, Crude Protein and Neutral Detergent Fiber of Three Varieties Passion Fruit (Passiflora spp) Shelves}

\begin{abstract}
Chemical composition and the potential and effective degradabilities of dry matter (DM), crude protein (CP) and neutral detergent fiber (NDF) of passion fruit residue (shelves) were studied in the varieties yellow (Passiflora edulis f. Flavicarpa Degener), purple (Passiflora edulis Sims) and sweet (Passiflora alata) and in the mixture of yellow and purple varieties. DM intake, ruminal concentrations of $\mathrm{N}$-ammonium, volatiles fatty acids (VFA) and $\mathrm{pH}$, and rate of liquid and solid rumen digesta flows were also studied. The residues (shelves) in natura presented a high moisture content, the purple variety showed the highest DM content (17.01\%) and the yellow the lowest (10.78\%). The CP contents ranged from $9.82 \%$ in DM, for the yellow variety to $7.53 \%$ for the sweet, while the corresponding P contents were $.13 \%$ for the sweet and $0.08 \%$ for the mixture. The contents of Ca, FDN and FDA showed no difference between varieties. Potential degradabilities of DM, CP and FDN reached the highest level after 48 hours incubation time. A significant interaction between incubation time and variety was observed for the degradability of DM, CP and FDN. The degradabilities of PB and FDN were affected by the varieties. The ED values for FDN were, respectively, 45.85 and $34.61 \%$. The average DM intake was 16.9 $\mathrm{kg}$ /animal, equivalent to $3.27 \%$ of live weight or $156.11 \mathrm{~g} / \mathrm{kg}^{0.75}$, when dried shelves (residue) with $90 \%$ of DM was fed. Rumen VFA concentrations ranged from 7.76 to 10.87 mmoles $/ 100 \mathrm{~mL}$, pH from 6.03 to 6.75 and $\mathrm{N}$-ammonium from 4.93 to $9.86 \mathrm{mg} / 100 \mathrm{~mL}$.
\end{abstract}

Key Words: chemical composition, degradability, passion fruit, ruminal parameters

\section{Introdução}

A utilização de resíduos agro-industriais na alimentação de ruminantes reveste-se de grande importância, já que um terço dos cereais produzidos no mundo é destinado aos animais domésticos, em detrimento de grande parcela da população mundial, caren- te de melhor alimentação. $\mathrm{O}$ uso de resíduos poderia liberar parcela significativa de nutrientes a essa população e, ao mesmo tempo, proporcionar fontes alternativas de alimentos menos nobres aos ruminantes (Mattos, 1990, citado por ZAGATTO, 1992).

MANTEROLA et al. (1992), estudando o valor nutritivo e a utilização de resíduos hortifrutícolas e

\footnotetext{
1 Parte da Dissertação de Mestrado apresentada pelo primeiro autor, à Universidade Estadual do Norte Fluminense, Campos dos Goytacazes, RJ.

2 Médico veterinário, UFV, MS em Produção Animal, CCTA, UENF.

3 Docente LZNA, CCTA, UENF.

4 Docente LZNA, CCTA, UENF, 28015-620 Campos dos Goytacazes, RJ, Bolsista do CNPq.
} 
agro-industriais na alimentação de ruminantes, concluíram que, em todos os países, existe grande diversidade e quantidade de resíduos, com diferentes potenciais alimentícios. Entretanto, a maioria destes resíduos se perde ou é subutilizada, em função do pouco conhecimento de seu valor nutritivo e suas limitações quanto à resposta do animal, com a sua inclusão na dieta.

O Brasil possui enorme quantidade de resíduos e subprodutos, da agricultura e da agroindústria, com potencial de uso na alimentação de ruminantes. As limitações para a transformação dos resíduos em subprodutos para alimentação animal estão ligadas à deficiência e/ou a desequilíbrios nas características nutricionais do resíduo e aos custos com a coleta, o transporte e, geralmente, o tratamento necessário para melhoria de seu valor nutritivo (BURGI, 1992).

O município de São Francisco de Itabapoana, situado na região Norte do Estado do Rio de Janeiro, possui grande vocação para a fruticultura, destacando-se a cultura do maracujá (Passiflora spp), que ocupa área entre 1200 e 1500 ha. Como a produtividade média de maracujá, nesta região, gira em torno de 20 t/ha, calcula-se que o potencial de produção é de 24.000 a 30.000 t/ano. Trabalhos realizados por OLIVEIRA et al. (1980) indicaram que $62,10 \%$ do fruto constituem-se de casca, o que indica potencial de resíduo de até 18.680 toneladas por ano na região. Visto que esta produção acontece no período seco, que vai de abril a setembro, pode-se considerá-la alternativa viável para alimentação do gado na época seca.

O resíduo do maracujá, representado pela casca mais sementes, é constituído pelo óleo (da semente), pela pectina e pelo conteúdo mineral da casca, o que viabiliza sua utilização na ração animal (OTAGAKI, 1958; PRUTHI, 1963; e ARIKI et al., 1977). Segundo ARIKI et al. (1977), a composição química da casca desidratada do fruto do maracujá amarelo é: matéria seca (MS) 82,34\%; proteína bruta (PB) 8,70\%; extrato etéreo (EE) 2,43\%; fibra bruta (FB) 29,37\%; matéria mineral (MM) 7,75\%; e extrato nãonitrogenado 34,09\% . Já OTAGAKI (1958) e PRUTHI (1963), analisando a polpa desidratada do maracujá, encontraram, respectivamente, a seguinte composição química: MS, 16,80 e 18,08\%; PB, 4,58 e 2,56\%; EE, 0,33 e $0,54 \%$; e FB, 25,66 e 27,71\%.

REIS (1994), trabalhando com resíduo de maracujá, encontrou 19,00\% MS, 10,50\% PB, 59,50\% fibra em detergente neutro (FDN) e 52,37\% fibra em detergente ácido (FDA), com base na matéria seca.

O objetivo deste trabalho foi avaliar a composição químico-bromatológica do resíduo da casca do fruto do maracujazeiro (Passiflora spp), em termos de MS, PB, FDN, FDA, Ca, P e energia bruta (EB), o consumo, a degradabilidade in situ, a taxa de passagem e os teores de ácidos graxos voláteis, nitrogênio amoniacal e pH do líquido do rúmen de bovinos alimentados com este resíduo.

\section{Material e Métodos}

O presente trabalho foi conduzido no Laboratório de Zootecnia e Nutrição Animal (LZNA) da Universidade Estadual do Norte Fluminense (UENF), em Campos dos Goytacazes, RJ. O Município de Campos dos Goytacazes localiza-se na Região Norte do Estado do Rio de Janeiro, $21^{\circ} 44^{\prime}$ 47' de latitude, $41^{\circ} 18^{\prime} 24^{\prime \prime}$ de longitude, altitude de $12 \mathrm{~m}$, apresentando temperaturas médias anuais de máximas e mínimas, respectivamente, de 27,1 e 21,4 e precipitação anual de $1023 \mathrm{~mm}$. Segundo KÖEPPEN (1948), a região é classificada como tropical chuvosa de clima de bosque (AM).

Foram utilizados quatro novilhos mestiços 7/8 holandês-zebu, fistulados no rúmen, com quatro anos de idade e peso vivo médio de $500 \mathrm{~kg}$. Para se determinar a degradabilidade in situ, foi usado período de 15 dias para adaptação dos animais à alimentação. Calculou-se consumo de $2 \% \mathrm{MS}$ por peso vivo, oferecendo-se inicialmente uma dieta com $30 \%$ de casca de maracujá seca e moída e $70 \%$ de feno de capim colonião (Panicum maximum Jacq). Estas porcentagens foram modificadas, atingindo-se os valores de $70 \%$ de casca de maracujá e $30 \%$ de feno ou seja: 7,80 kg de casca de maracujá e 4,0 kg de feno, oferecida em partes iguais, às 8 e $15 \mathrm{~h}$. No período de determinação de consumo voluntário, taxa de passagem da digesta ruminal, ácidos graxos voláteis (AGV), pH e amônia ruminal $\left(\mathrm{N}-\mathrm{NH}_{3}\right)$, os animais receberam exclusivamente casca de maracujá. Os animais foram mantidos em baias individuais, com água e sal mineralizado à vontade.

Os maracujás amarelo (Passiflora edulis f. Flavicarpa Degener) e roxo (Passiflora edulis Sums) foram coletados na Cooperativa de Fruticultores de Imburi de Barra Ltda. (COOPERFRUT), situada no distrito de Praça João Pessoa no município de São Francisco do Itabapoana (RJ). O maracujá doce (Passiflora alata) foi obtido no município de Muqui (ES).

O maracujá foi levado ao LZNA da UENF, onde foi extraído o suco e preparado para as análises químico-bromatológicas, para a degradabilidade in 
1150 Rev. bras. zootec.

situ, de acordo com SILVA (1990). O material para as análises foi moído em moinho com peneira com malha de $3 \mathrm{~mm}$ de diâmetro. Para o material a ser incubado, utilizou-se peneira com malha de $5 \mathrm{~mm}$ de diâmetro. O resíduo utilizado para o estudo do consumo de matéria seca e as determinações do $\mathrm{pH}$ e níveis de $\mathrm{N}$-amoniacal e ácidos graxos voláteis no líquido ruminal foi fornecido pela fábrica de suco da Cooperfrut (Cooperativa dos Fruticultores de Imburi de Barra - São Francisco de Itabapoana-RJ), seco ao sol e, depois, moído em máquina forrageira de martelo (farelo de casca de maracujá).

Os tratamentos consistiram em: T1 - casca de maracujá amarelo (Passiflora edulis f. Flavicarpa Degener); T2 - casca de maracujá roxo (Passiflora edulis Sums); T3 - mistura da casca de maracujá amarelo (50\%) e maracujá roxo (50\%); e T4 - casca de maracujá doce (Passiflora alata).

Para a análise químico-bromatológica do resíduo da casca de maracujá, foram coletadas quatro amostras para cada um dos tratamentos, distribuídos em delineamento inteiramente casualizado, de acordo com o seguinte modelo estatístico para todas as variáveis:

$$
Y_{i j}=\mu+t i+E_{i j}
$$

em que $\mu$ é média geral das observações; $t_{i}$, efeito da variedade $\mathrm{i}(\mathrm{i}=1,2,3,4)$; e $\mathrm{E}_{\mathrm{ij}}$, erro experimental (amostra/variedade).

As determinações de MS, PB, FDN e FDA, EB, Ca e P foram feitas de acordo com SILVA (1990).

Para avaliar a degradabilidade, utilizou-se a técnica do saco de náilon, proposto por MEHREZ e ORSKOV (1977), obedecendo-se algumas recomendações propostas por NOCEK (1988), como porosidade do saco e relação entre tamanho da amostra e área do saco e tamanho da partícula.

Os sacos de náilon mediam 14 x $6,5 \mathrm{~cm}$, com abertura de malha de $50 \mu \mathrm{m}$. Antes de receberem as amostras, estes foram identificados e levados para estufa com ventilação forçada de ar, durante 12 horas a $65^{\circ} \mathrm{C}$. A seguir, colocaram-se em torno de 3,4 $\mathrm{g}$ de amostra em cada saco, fechando-se imediatamente com liga de borracha. Os sacos, presos a uma corrente, foram introduzidos no rúmen pela fístula ruminal.

Para cada amostra e tempo de incubação, foram feitas quatro repetições, obedecendo-se a relação de $20 \mathrm{mg}$ de amostra $/ \mathrm{cm}^{2}$ da área de superfície dos sacos.

Os sacos foram incubados nos tempos de $0,6,12$, 24, 48, 72 e 96 horas. Os sacos correspondentes ao tempo 0 não foram incubados, mas sofreram o mesmo processo de lavagem dos demais. A sequiência de aplicação dos tratamentos nos bovinos encontra-se na Tabela 1.

Após cada tempo pré-determinado para a incubação, os sacos foram retirados do rúmen, lavados para tirar as partículas de material ruminal aderidas à superfície externa dos sacos, colocados em um saco plástico e, após, levados ao congelador.

Após o término do período, o material correspondente foi levado ao laboratório, sendo lavado devidamente para extrair os componentes solúveis que ainda permaneciam nos sacos após sua remoção do rúmen. Uma vez lavado, o material foi colocado em estufa com ventilação forçada à temperatura de $80^{\circ} \mathrm{C}$ por 12 horas e, depois, pesado.

No estudo de degradabilidade in situ, foi adotado um esquema em parcela sub-dividida no delineamento quadrado latino $4 \times 4$, análise foi feita de acordo com o modelo:

$$
\begin{aligned}
& \mathrm{Y}_{\mathrm{ijklr}}=\mu+\mathrm{l}_{\mathrm{i}}+\mathrm{c}_{\mathrm{j}}+\mathrm{v}_{\mathrm{k}}+\mathrm{e}_{\mathrm{ijk}}+\mathrm{t}_{1}+\mathrm{v}_{\mathrm{k}} \mathrm{t}_{\mathrm{kl}}+\mathrm{e}_{\mathrm{ijklr}} \\
& \text { em que } \\
& \mu \quad=\mathrm{i}=\mathrm{j}=[1,4] \\
& \mu \quad=\text { efeito da média geral; } \\
& l_{\mathrm{i}} \quad=\text { efeito da linha } \mathrm{i}-\text { período, } \mathrm{i}=1,2,3,4 ; \\
& \mathrm{c}_{\mathrm{j}} \quad=\text { efeito da coluna - animal, } \mathrm{j}=1,2,3,4 ; \\
& \mathrm{v}_{\mathrm{k}} \quad=\text { efeito da variedade, }{ }_{\mathrm{k}}=1,2,3,4 ; \\
& \mathrm{e}_{\mathrm{ijk}} \quad=\text { erro (a) variável aleatória normal indepen- }
\end{aligned}
$$
dente distribuída com média $\varnothing$ e variância $\sigma \mathrm{A}^{2}$;

$\mathrm{t}_{l} \quad=$ efeito do tempo $1=1,2, \ldots 7$;

$\mathrm{v} \cdot \mathrm{t}_{\mathrm{kl}}=$ efeito da interação variedade $\mathrm{x}$ tempo; $\mathrm{e}$

$\mathrm{e}_{\mathrm{ijklr}}=$ variável aleatória normal independente distribuída com média $\varnothing$ e variância $\sigma \mathrm{e}^{2}$.

As porcentagens do desaparecimento da MS, PB e FDN dos alimentos foram calculadas pela diferença entre as quantidades de amostras incubadas e os resíduos de matéria seca, proteína bruta e fibra detergente neutro, após o tempo de incubação. Os dados referentes à degradabilidade dos resíduos estudados foram submetidos à análise de variância do SAS (1990), considerando-se período, animal, tempo e as variedades dos resíduos do fruto do maracujá (casca).

Estes dados, posteriormente, foram ajustados ao modelo matemático, proposto por MEHREZ e ORSKOV (1977): $\mathbf{D}=\mathbf{a}+\mathbf{b}\left(\mathbf{1}-\mathbf{e}^{-\mathbf{c t}}\right)$ em que $\mathbf{D}$ é a quantidade de nutriente degradada no tempo "t $t$ "; a, a fração rapidamente solúvel em água; b, a fração insolúvel em água, mas potencialmente degradável; e c, a taxa de degradação da fração b.

Para a degradabilidade efetiva (DE), os cálculos foram feitos utilizando-se a equação de ORSKOV e McDONALD (1979): $\mathrm{DE}=\mathrm{a}+(\mathrm{bc}) / \mathrm{c}+\mathrm{k}$, em que $\mathrm{k}$ é a taxa de passagem e (a) (b) e (c) são os mesmos 
da equação anterior.

As taxas de passagem da digesta pelo rúmen foram determinadas com o auxílio do cobalto - EDTA, indicador da fase líquida, e o cromo-mordante, indicador da fase sólida (UDEN et al., 1980).

Os indicadores foram fornecidos em dose única, quando os animais só estavam consumindo casca de maracujá (mistura), e após a retirada de amostra do material do rúmen, correspondente ao tempo zero.

A dose de Co-EDTA foi de 5 g, diluída em $400 \mathrm{~mL}$ de água desionizada e colocada no rúmen via fístula, com o auxílio de um funil acoplado à mangueira de borracha. $\mathrm{O} \mathrm{Cr}$-mordante foi colocado diretamente no rúmen, na quantidade de $75 \mathrm{~g}$ por animal, e embrulhado em papel.

Para a análise de Co-EDTA, foram coletadas amostras do conteúdo ruminal antes e 2, 4, 6, 8, 12, 24, 30, 36, 72 horas após a alimentação. O tempo foi contado após a colocação do indicador no rúmen.

O material foi coletado diretamente no rúmen, sendo separada a parte líquida da parte sólida, por intermédio da filtragem do material em gaze dupla, sendo acondicionada em frascos de vidro, que foram imediatamente colocados no congelador.

$\mathrm{Na}$ coleta das amostras da fase sólida, os tempos utilizados foram os mesmos da fase líquida. $\mathrm{Na}$ filtragem do material, a parte que ficou na gaze, em torno de $100 \mathrm{~g}$ por amostra, foi levada ao congelador e, posteriormente, seca a $65^{\circ} \mathrm{C}$ durante 72 horas. Após, foi moída e guardada em frascos, para subseqüente análise.

Para determinação da concentração do cobalto, o líquido ruminal foi centrifugado a $10.000 \mathrm{rpm}$ durante 15 minutos e o sobrenadante foi levado ao espectrofotômetro de absorção atômica para leitura. No preparo das amostras da fase sólida, seguiu-se a técnica descrita por SILVA (1990) e as leituras para o cromo foram feitas no espectrofotômetro de absorção atômica.

Determinou-se o consumo durante onze dias, sendo que, para este estudo, pesou-se determinada quantidade de farelo de casca de maracujá seca e moída, fornecendo-a aos animais, de forma individual e duas vezes ao dia, 8 e 15 h. Utilizaram-se três animais e os resultados obtidos foram expressos em médias, não só para consumo, como também para AGV, pH e $\mathrm{N}-\mathrm{NH}_{3}$ e taxa de passagem das fases sólida e líquida da digesta. A concentração de ácidos graxos voláteis (AGV), no líquido ruminal, foi determinada antes da alimentação e 2, 4, 6, 8, 10, 24 horas, estando os animais se alimentando exclusivamente de farelo de casca de maracujá.

A coleta do líquido ruminal foi feita manualmente, retirando-se pela fístula ruminal sólidos e líquidos, que foram espremidos em um funil com gaze. Ao líquido ruminal filtrado (em torno de $40 \mathrm{~mL}$ ), adicionaram-se $8 \mathrm{~mL}$ de ácido fosfórico e sendo colocado no congelador. No preparo, o material foi centrifugado a $17.000 \mathrm{rpm}$, durante 15 minutos, pipetando-se $2 \mathrm{~mL}$ e acrescentando-se $1 \mathrm{~mL}$ de ácido metafosfórico a $20 \%$ e $0,2 \mathrm{~mL}$ de ácido fênico a $1 \%$. A determinação dos ácidos foi feita pelo método de cromatografia em fase gasosa, segundo WILSON (1971).

Na coleta do líquido ruminal, para a determinação do $\mathrm{N}$-amoniacal, foi adotado o mesmo procedimento já usado para AGV. Após a obtenção de $40 \mathrm{~mL}$ do líquido ruminal, adicionaram-se a esse líquido $4 \mathrm{~mL}$ de ácido sulfúrico. Após a filtragem, a concentração do $\mathrm{N}$-amôniacal foi determinada, utilizando-se $2 \mathrm{~mL}$ do filtrado em aparelho Kjeldahl e seguindo-se as recomendações descritas por SILVA (1990).

A determinação do $\mathrm{pH}$ ruminal foi feita no líquido retirado, seguindo o mesmo procedimento já descrito para AGV e amônia. Após a filtragem do líquido em gaze, determinou-se o $\mathrm{pH}$ com peagâmetro portátil.

\section{Resultados e Discussão}

No que se refere à composição dos resíduos das diferentes variedades e da mistura (Tabela 2), a variedade roxa foi a que apresentou a maior porcentagem de MS, possivelmente, uma característica própria da variedade. Durante o beneficiamento do suco no laboratório, no momento do corte, o fruto era mais rígido. Os dados observados sobre teor de matéria seca conferem com os dados de ARIKI et al. (1977). A variedade amarela apresentou menor teor de matéria seca, podendo ser também uma caracte-

Tabela 1 - Seqüência de incubação das amostras nos bovinos

Table 1 - Samples incubation sequence in cattle

\begin{tabular}{|c|c|c|c|c|}
\hline & \multicolumn{4}{|c|}{$\begin{array}{c}\text { Bovino } \\
\text { Cattle }\end{array}$} \\
\hline Período & $\mathrm{N}^{\circ} 1$ & $\mathrm{~N}^{\circ} 2$ & $\mathrm{~N}^{\circ} 3$ & $\mathrm{~N}^{\circ} 4$ \\
\hline Periods & & & & \\
\hline I & A & $\mathrm{M}$ & $\mathrm{R}$ & D \\
\hline II & $\mathrm{R}$ & A & $\mathrm{D}$ & M \\
\hline III & D & $\mathrm{R}$ & M & A \\
\hline IV & M & D & A & $\mathrm{R}$ \\
\hline
\end{tabular}

$\mathrm{A}=$ amarelo (yellow), $\mathrm{R}=$ roxo (purple), $\mathrm{D}=$ doce (sweet), $\mathrm{M}=$ mistura (mixture). 
1152 Rev. bras. zootec.

Tabela 2 - Teor médio de matéria seca (MS), proteína bruta $(\mathrm{PB})$, fibra em detergente neutro $(F D N)$, fibra em detergente ácido (FDA), cálcio $(\mathrm{Ca})$, fósforo $(\mathrm{P})$ e energia bruta $(\mathrm{EB})$ dos resíduos (casca) das variedades de maracujá (Passiflora spp)

Table 2 - Mean content of dry matter (MS), crude protein (PB), neutral detergent fiber (FDN), acid detergent fiber (FDA), calcium (Ca), phosphorus $(P)$ e gross energy (GE) of residues (shelves) of passion fruits varieties (Passiflora spp)

\begin{tabular}{|c|c|c|c|c|c|c|c|}
\hline \multirow{3}{*}{$\begin{array}{c}\text { Variedade } \\
\text { Varities }\end{array}$} & $\begin{array}{l}\text { MS } \\
D M\end{array}$ & $\begin{array}{l}\mathrm{PB} \\
C P\end{array}$ & $\mathrm{Ca}$ & $\mathrm{P}$ & $\begin{array}{l}\text { FDN } \\
N D F\end{array}$ & $\begin{array}{l}\text { FDA } \\
A D F\end{array}$ & \multirow{3}{*}{$\begin{array}{c}\mathrm{EB} \\
G E \\
(\mathrm{Cal} / \mathrm{g} \mathrm{MS})\end{array}$} \\
\hline & \multirow{2}{*}{$\begin{array}{c}D M \\
\%\end{array}$} & \multirow{2}{*}{\multicolumn{5}{|c|}{$\begin{array}{l}\% \text { na MS } \\
\% \text { in } M S\end{array}$}} & \\
\hline & & & & & & & \\
\hline Amarelo (A) & $10,78^{d}$ & $9,82^{\mathrm{a}}$ & $0,35^{\mathrm{a}}$ & $0,08^{\mathrm{b}}$ & $44,16^{\mathrm{a}}$ & $35,85^{\mathrm{a}}$ & $3.706,14^{\mathrm{ab}}$ \\
\hline Yelow $(A)$ & & & & & & & \\
\hline Roxo (R) & $17,01^{\mathrm{a}}$ & $8,56^{\mathrm{ab}}$ & $0,34^{\mathrm{a}}$ & $0,09^{a b}$ & $43,75^{\mathrm{a}}$ & $35,06^{\mathrm{a}}$ & $3.582,45^{\mathrm{b}}$ \\
\hline Purple (R) & & & & & & & \\
\hline Mistura (AxR) & $13,81^{b}$ & $9,24^{\mathrm{a}}$ & $0,28^{a}$ & $0,08^{b}$ & $37,69^{\mathrm{a}}$ & $30,06^{\mathrm{a}}$ & $3.833,13^{\mathrm{a}}$ \\
\hline Mixture $(A x R)$ & & & & & & & \\
\hline Doce (D) & $12,07^{\mathrm{c}}$ & $7,53^{b}$ & $0,33^{\mathrm{a}}$ & $0,13^{\mathrm{a}}$ & $39,07^{\mathrm{a}}$ & $31,10^{\mathrm{a}}$ & $3.658,63^{\mathrm{ab}}$ \\
\hline
\end{tabular}

Médias, na coluna, seguidas de letras diferentes são diferentes $(P>0,05)$ pelo teste Tukey.

Means, within a column, followed by different letters are different $(P>.05)$ by Tukey test.

rística da variedade, ou função da não-seleção de frutos maduros pela indústria, o que acarreta o esmagamento de bastante frutos verdes, conforme observação feita no local.

Em relação ao teor de $\mathrm{PB}$, não houve diferença entre as variedades amarela e roxa e a mistura de ambas. Esse fato, possivelmente, é explicado pelas condições de cultivo semelhantes, como solo, adubações, entre outros, o que já não ocorreu com a variedade doce, que apresentou menor $(\mathrm{P}<0,05)$ teor de $\mathrm{PB}$, cujos frutos foram coletados em pés nativos, sem qualquer tipo de trato cultural, principalmente adubação nitrogenada. Na literatura consultada, PRUTHI (1963) obteve para a variedade roxa média de 2,27\%; OTAGAKI (1958), 4,58\% para a amarelo; e ARIKI et al. (1977) e REIS (1994), 8,70 e 10,50\% PB.

Não houve diferença entre variedades quanto aos teores de FDN, que estiveram na faixa de 39 a $44 \%$, e FDA, de 31 a 35\%. REIS (1994) encontrou 59,50 e $52,27 \%$, respectivamente, para os teores de FDN e FDA, resultados estes superiores aos encontrados neste trabalho.

Quanto ao teor de Ca, não houve diferença entre as variedades. Em comparação com a literatura, PRUSTH (1963) obteve para maracujá roxo 0,28\%, valor inferior ao encontrado para essa variedade no presente trabalho $(0,33 \%)$.

Houve diferença $(\mathrm{P}<0,05)$ entre as variedades doce e amarela, com relação aos teores de P (Tabela 2), a qual pode ser atribuída à procedência dos frutos. A variedade doce é proveniente de maracujazeiros nativos, com vários anos de implantação, apresentando, por isso, sistema radicular mais complexo e com melhor eficiência para absorção. Em comparação com dados de literatura, PRUSTH (1963) observou $0,22 \%$ para a variedade roxa - resultado maior que o obtido neste trabalho $(0,09 \%)$.

Embora a o teor de EB tenha pouco significado em termos de valor nutritivo, houve diferença $(\mathrm{P}<0,01)$ entre as variedades estudadas; a mistura (A $x \mathrm{R})$ foi a que apresentou maior quantidade de energia e a roxa, a menor. Os teores obtidos ficaram abaixo do esperado, provavelmente em função dos altos teores de cinza. Degradabilidade in situ

As porcentagens médias de desaparecimento da MS, PB e FDN do resíduo (casca) das três variedades de maracujá e da mistura da amarela e roxa, incubadas no rúmen, podem ser observadas na Tabela 3. As degradabilidades médias atingiram os maiores valores, praticamente, às 24 horas. Houve grande fração solúvel para proteína. A parede celular foi degradada, em até $65 \%$ na mistura, observando-se valor de $52 \%$ para a variedade doce.

Resumo da análise de variância dos coeficientes de degradabilidade da MS, PB e FDN encontra-se na Tabela 4.

Pode-se observar que o fator período não foi significativo para MS, PB e FDN. O efeito de animal foi significativo $(\mathrm{P}<0,01)$ para $\mathrm{PB}$, o que confirma, em parte, os resultados relatados por MEHREZ e ORSKOV (1977). DESCHAMPS (1991), trabalhando em diferentes experimentos com vários alimentos, também encontrou diferenças significativas $(\mathrm{P}<0,05)$ entre animais. Não houve efeito de variedade na 
VIEIRA et al.

Tabela 3 - Porcentagem média de desaparecimento da matéria seca (MS), proteína bruta (PB) e fibra em detergente neutro (FDN) dos resíduos (casca) de maracujá das variedades amarela, roxa, mistura e doce, em função do tempo de incubação

Table 3 - Mean disappearance percentages of dry matter (MS), crude protein (PB) and neutral detergent fiber (FDN) of residues (shelves) of yellow, purple, mixture and sweet passion fruits varieties, on the incubation time

\begin{tabular}{|c|c|c|c|c|c|c|c|c|c|c|c|c|}
\hline \multirow{4}{*}{$\begin{array}{l}\text { Tempo de } \\
\text { Incubação } \\
\text { Incubation } \\
\text { time }\end{array}$} & \multicolumn{12}{|c|}{$\begin{array}{c}\text { Variedade } \\
\text { Variety }\end{array}$} \\
\hline & \multirow{2}{*}{\multicolumn{3}{|c|}{$\begin{array}{c}\text { Amarela (A) } \\
\text { Yellow }(A)\end{array}$}} & \multirow{2}{*}{\multicolumn{3}{|c|}{$\begin{array}{l}\text { Roxa (R) } \\
\text { Purple (R) }\end{array}$}} & \multirow{2}{*}{\multicolumn{3}{|c|}{$\begin{array}{r}\text { Mistura }(\mathrm{A}+\mathrm{R}) \\
\text { Mixture }(A+R)\end{array}$}} & \multirow{2}{*}{\multicolumn{3}{|c|}{$\begin{array}{l}\text { Doce (D) } \\
\text { Sweet }(D)\end{array}$}} \\
\hline & & & & & & & & & & & & \\
\hline & MS & $\mathrm{PB}$ & FDN & $\overline{\mathrm{MS}}$ & PB & FDN & MS & PB & FDN & MS & PB & FDN \\
\hline 0 & 34 & 64 & 6 & 23 & 51 & 12 & 31 & 60 & 10 & 42 & 49 & 4 \\
\hline 6 & 49 & 56 & 25 & 38 & 40 & 24 & 48 & 57 & 27 & 55 & 47 & 20 \\
\hline 12 & 68 & 81 & 47 & 67 & 79 & 40 & 68 & 84 & 49 & 71 & 78 & 39 \\
\hline 24 & 76 & 88 & 55 & 78 & 91 & 56 & 78 & 92 & 63 & 75 & 77 & 48 \\
\hline 48 & 80 & 94 & 62 & 78 & 91 & 56 & 80 & 92 & 64 & 78 & 87 & 52 \\
\hline 72 & 80 & 93 & 61 & 78 & 89 & 57 & 80 & 92 & 64 & 78 & 88 & 52 \\
\hline 96 & 79 & 90 & 61 & 78 & 91 & 57 & 80 & 93 & 65 & 78 & 88 & 52 \\
\hline
\end{tabular}

degradabilidade da MS, mas houve significância $(\mathrm{P}<0,01)$ para $\mathrm{PB}$ e FDN, indicando que para esses fatores as variedades possuem comportamento diferente no rúmen. Como se esperava, o fator tempo teve alta significância $(\mathrm{P}<0,01)$ para todas as variedades estudadas, para os teores de MS, PB e FDN, visto que os resultados tenderam a se estabilizar após as $24 \mathrm{~h}$ (Tabela 3), com índices bastante altos, expressivos, em se tratando de resíduos.

Constam da Tabela 5 equações de regressão da degradabilidade in situ das variedades de maracujá amarelo, roxo, amarelo x roxo e doce, para MS, PB e FDN, em função do tempo de incubação. As estimativas dos coeficientes a, b, e c das equações ajustadas para as degradabilidades potenciais, segundo o modelo matemático, proposto por MEHREZ

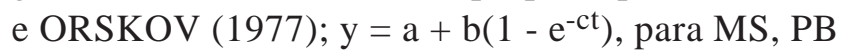
e FDN, encontram-se nas Tabelas 6, 7 e 8.

Os valores da fração solúvel em água "a" (Tabela 6) foram relativamente altos para a matéria seca. A variedade roxa apresentou a menor fração solúvel e o coeficiente $b$ (parte insolúvel, mas potencialmente degradável) foi o maior, provavelmente, em função de seu maior conteúdo de fibra. Quanto à taxa de degradação, as variedades tiveram comportamento semelhante. Comparando com os resultados de TEIXEIRA et al. (1996), que trabalharam com caroço de algodão e milho em diferentes formas físicas, estes resultados são semelhantes.

Os resultados de GOMES (1991) indicaram que a taxa de degradação "c" foi bem menor para fenos de capim-elefante napier e cameroon e palha arroz, respectivamente, 4,$0 ; 3,7 ;$ e $2,7 \% / \mathrm{h}$. A extensão $(a+b)$ da degradação do maracujá foi bem maior que a dos fenos e da palha.

Quanto à taxa de degradação da PB (Tabela 7), pode-se verificar que a mistura das variedades amarela e roxa foi a que degradou mais rápido e as variedades amarela e doce, as que se degradaram mais lentamente. As frações da PB solúveis em água, na variedade amarelo e na mistura, apresentaram valores bastante elevados $58 \%$. A variedade amarela e a mistura foram as que apresentaram maiores teores de PB total. Comparando com os resultados de TEIXEIRA et al. (1996), em que a ração contendo milho moído e caroço algodão moído também apresentou coeficiente "a" alto, em torno de $54,0 \%$, pode-se concluir que o coeficiente "a" elevado do maracujá está relacionado ao tamanho das partículas ou a elevados teores de compostos não-nitrogenados. As taxas de degradação de PB "c" variaram de 6 a 9\%/h. É importante conhecer as taxas de degradação da proteína, pois facilita a redução das perdas dos compostos nitrogenados no rúmen, fornecendo carboidratos e proteínas com taxas de degradação similares.

$\mathrm{Na}$ fração solúvel da FDN (a), observam-se (Tabela 8) diferenças entre as variedades, sendo que a roxo foi a que apresentou a maior fração (10\%) e a doce, a menor (2\%). Para parte insolúvel em água, mas potencialmente degradada (B), pode-se verificar que os valores foram bastante semelhantes entre si.

Comparando com os resultados de TEIXEIRA et al. (1996), que trabalharam com milho e farelo de algodão em diferentes tamanhos de partículas (inteiros e triturados), observa-se que a ração que continha milho triturado $(61,5 \%)$ e caroço de algodão inteiro 
1154 Rev. bras. zootec.

Tabela 4 - Resumo da análise de variância da degradabilidade potencial da matéria seca (MS), proteína bruta (PB) e fibra em detergente neutro (FDN) do resíduo (casca) de maracujá

Table 4 - Summary of the analysis of variance of potential degradability of dry matter (MS), crude protein $(P B)$ and neutral detergent fiber (FDN) of the residue (shelves) of passion fruits

\begin{tabular}{|c|c|c|c|c|c|}
\hline & $\begin{array}{l}\mathrm{FV} \\
\mathrm{SV}\end{array}$ & $\begin{array}{l}\text { gl } \\
d f\end{array}$ & $\begin{array}{l}\text { MS } \\
D M\end{array}$ & $\begin{array}{l}\mathrm{PB} \\
C P\end{array}$ & $\begin{array}{l}\text { FDN } \\
N D F\end{array}$ \\
\hline Animal & & 3 & $0,0022(\mathrm{NS})$ & $0,042(\mathrm{~S})$ & $0,1197(\mathrm{NS})$ \\
\hline Período & & 3 & 0,0135 (NS) & 0,113 (NS) & $0,0014(\mathrm{NS})$ \\
\hline Period & & & & & \\
\hline $\begin{array}{l}\text { Erro (a) } \\
\text { Error }(a)\end{array}$ & & 6 & 0,0033 & 0,0039 & 0,0171 \\
\hline $\begin{array}{l}\text { Parcela } \\
\text { Parcel }\end{array}$ & & 15 & & & \\
\hline & $\begin{array}{l}\text { Regressão } \\
\text { Regression }\end{array}$ & 3 & $0,2578(\mathrm{~S})$ & $0,1490(\mathrm{~S})$ & $0,03554(\mathrm{~S})$ \\
\hline var.1 & $\begin{array}{l}\text { Desvio da regressão } \\
\text { Deviation of regression }\end{array}$ & 3 & $0,0042(\mathrm{NS})$ & $0,0344(\mathrm{~S})$ & $0,0050(\mathrm{NS})$ \\
\hline & $\begin{array}{l}\text { Regressão } \\
\text { Regression }\end{array}$ & 3 & $0,2561(\mathrm{~S})$ & $0,3618(\mathrm{~S})$ & $0,2562(\mathrm{~S})$ \\
\hline var.2 & $\begin{array}{l}\text { Desvio da regressão } \\
\text { Deviation of regression }\end{array}$ & 3 & $0,1272(\mathrm{~S})$ & $0,0639(\mathrm{~S})$ & $0,0171(\mathrm{NS})$ \\
\hline & $\begin{array}{l}\text { Regressão } \\
\text { Regression }\end{array}$ & 3 & $0,2958(\mathrm{~S})$ & $0,1397(\mathrm{~S})$ & $0,3749(\mathrm{~S})$ \\
\hline var.3 & $\begin{array}{l}\text { Desvio da regressão } \\
\text { Deviation of regression }\end{array}$ & 3 & 0,0049(NS) & 0,0050(NS) & $0,0156(\mathrm{NS})$ \\
\hline & $\begin{array}{l}\text { Regressão } \\
\text { Regression }\end{array}$ & 3 & $0,1612(\mathrm{~S})$ & $0,2235(\mathrm{~S})$ & $0,2906(\mathrm{~S})$ \\
\hline var.4 & $\begin{array}{l}\text { Desvio da regressão } \\
\text { Deviation of regression }\end{array}$ & 3 & 0,0012(NS) & 0,0350 (NS) & 0,0039 (NS) \\
\hline $\begin{array}{l}\text { Erro (b) } \\
\text { Error }(b)\end{array}$ & & 72 & 0,0025 & 0,0088 & 0,0072 \\
\hline
\end{tabular}

$\mathrm{S}=$ significativo a $1 \%$ de probabilidade pelo teste $\mathrm{F}(\mathrm{S}=$ significant at $1 \%$ probability by $\mathrm{F}$ test $)$.

NS = não-significativo (NS = not significant).

Tabela 5 - Regressão da degradabilidade in situ das variedades de maracujá para matéria seca (MS), proteína bruta (PB) e fibra em detergente neutro (FDN), em função do tempo de incubação, e os respectivos coeficiente de determinação $\left(R^{2}\right)$

Table 5 - Regression equations of in situ degradabilities of passion fruit varieties, for dry matter (MS), crude protein (PB) and neutral detergent fiber (FDN), on the incubation time and the respective coefficients of determination $\left(R^{2}\right)$

\begin{tabular}{|c|c|c|c|}
\hline & $\begin{array}{c}\text { Variedade } \\
\text { Variety }\end{array}$ & $\begin{array}{l}\text { Regressão } \\
\text { Regression }\end{array}$ & $\mathrm{R}^{2}$ \\
\hline & MS & $\hat{\mathrm{Y}}=0,3257+0,4731(1-\mathrm{e}-0,0928 \mathrm{t})$ & 0,99 \\
\hline Amarelo & $\mathrm{PB}$ & $\hat{\mathrm{Y}}=0,5816+0,3533\left(1-\mathrm{e}^{-0,585 \mathrm{t}}\right)$ & 0,98 \\
\hline \multicolumn{4}{|l|}{ Yellow } \\
\hline \multirow[t]{2}{*}{ (A) } & FDN & $\hat{\mathrm{Y}}=0,0522+0,5653\left(1-\mathrm{e}^{-0,0912 \mathrm{t}}\right)$ & 0,97 \\
\hline & MS & $\hat{\mathrm{Y}}=0,2159+0,5751\left(1-\mathrm{e}^{-0,1168 t}\right)$ & 0,99 \\
\hline Roxo & PB & $\hat{\mathrm{Y}}=0,3689+0,5551\left(1-\mathrm{e}_{-} 0,0761 \mathrm{t}\right)$ & 0,97 \\
\hline \multicolumn{4}{|l|}{ Purple } \\
\hline \multirow[t]{2}{*}{ (R) } & FDN & $\hat{\mathrm{Y}}=0,1029+0,4764\left(1-\mathrm{e}^{0} 0,0805 \mathrm{t}\right)$ & 0,95 \\
\hline & MS & $\hat{\mathrm{Y}}=0,02956+0,5087\left(1-\mathrm{e}^{0} 0,0998 \mathrm{t}\right)$ & 0,99 \\
\hline Mistura & PB & $\hat{\mathrm{Y}}=0,5812+0,3494\left(1-\mathrm{e}^{0,0941 \mathrm{t}}\right)$ & 0,99 \\
\hline \multicolumn{4}{|l|}{ Mixture } \\
\hline \multirow[t]{2}{*}{$(\mathrm{AxR})$} & FDN & $\hat{Y}=0,0807+0,5760\left(1-{ }^{e-0,0915 t}\right)$ & 0,95 \\
\hline & MS & $\hat{\mathrm{Y}}=0,4090+03746\left(1-\mathrm{e}^{0} 0,0947 \mathrm{t}\right)$ & 0,99 \\
\hline \multirow{2}{*}{$\begin{array}{l}\text { Doce } \\
\text { Sweet } \\
\text { (D) }\end{array}$} & PB & $\hat{\mathrm{Y}}=0,4511+0,4333\left(1-\mathrm{e}_{-} 0,0614 \mathrm{t}\right)$ & 0,98 \\
\hline & FDN & $\hat{\mathrm{Y}}=0,0246+0,5008(1-\mathrm{e}-0,0915 \mathrm{t})$ & 0,97 \\
\hline
\end{tabular}

MS (DM); PB (CP); FDN (NDF). 
Tabela 6 - Estimativa dos coeficientes a, b e c das equações, ajustadas para degradabilidade potencial da matéria seca (MS) dos resíduos (casca) das variedades de maracujá e respectivos coeficientes de determinação $\left(R^{2}\right)$

Table 6 - Estimate of $a, b$ and $c$ coefficients of the adjusted equations for potential degradabilities of dry matter (MS) of residues (shelves) of passion fruits varieties and the respective coefficients of determination $\left(R^{2}\right)$

\begin{tabular}{lcccc}
\hline & \multicolumn{4}{c}{$\begin{array}{c}\text { Coeficiente } \\
\text { Coefficient }\end{array}$} \\
\cline { 2 - 4 } $\begin{array}{l}\text { Variedade } \\
\text { Variety }\end{array}$ & $\mathrm{a}$ & $\mathrm{b}$ & $\mathrm{c}$ & $\mathrm{R}^{2}$ \\
$\begin{array}{l}\text { Amarelo } \\
\text { Yellow }\end{array}$ & 33 & 47 & 0,09 & 0,99 \\
$\begin{array}{l}\text { Roxo } \\
\begin{array}{l}\text { Purple } \\
\text { Mistura }\end{array}\end{array}$ & 22 & 58 & 0,11 & 0,99 \\
$\begin{array}{l}\text { Mixture } \\
\text { Doce }\end{array}$ & 29 & 51 & 0,10 & 0,99 \\
Sweet & 29 & 51 & 0,10 & 0,99 \\
\hline
\end{tabular}

$(26,1 \%)$ apresentou fração "b" (potencialmente degradado) de $65 \%$ próximo da mistura (A x R), que obteve 58\%. Quanto ao "c", taxa de degradação, todas as variedades de maracujá apresentaram taxa maior que a das rações estudadas por TEIXEIRA et al. (1996). Em relação aos resultados de GOMES (1991), que trabalharam com fenos de capim-elefante e palha de arroz, observa-se que a mistura possui fração "b" semelhante ao feno de napier, mas possui taxa de degradação maior. Em relação ao feno de capim-elefante e palha de arroz, todos os resíduos das variedades de maracujá estudados possuem taxas de degradação maiores.

$\mathrm{Na}$ Tabela 9 encontram-se os valores das degradabilidades efetivas da MS, PB e FDN das cascas (resíduo) do maracujá. A taxa de passagem da fase sólida da digesta ruminal utilizada no cálculo foi $4,8 \%$.

Todas as variedades estudadas apresentaram valores elevados para a degradabilidade efetiva da MS, na taxa de passagem de $4,8 \%$, se comparados com os resultados de VILELA (1994), que encontraram, na taxa de passagem $5 \%$ por hora, valores de 68,$3 ; 50,4 ; 29,8 ; 32,6 ;$ e $14,3 \%$, para o farelo de soja, o fubá de milho, o capim-elefante, o farelo de algodão e o caroço de algodão, respectivamente.

Comparando com os resultados obtidos por TEIXEIRA et al. (1996), que trabalharam com rações contendo caroço de algodão e grão de milho em diferentes formas físicas, à taxa de passagem de $5 \%$ por hora, observa-se que para MS a degradabilidade efetiva da casca do maracujá foi maior, pois a maior porcentagem encontrada foi de $45 \%$ para a ração composta de milho e caroço de algodão moído. Para a degradabilidade
Tabela 7 - Estimativa dos coeficientes a, b e c das equações, ajustadas para degradabilidade potencial da proteína bruta (PB) dos resíduos (casca) das variedades de maracujá e respectivos coeficientes de determinação $\left(R^{2}\right)$

Table 7 - Estimate of $a, b$ and $c$ coefficients of the adjusted equations for potential degradabilities of crude protein $(P B)$ of residues (shelves) of passion fruits varieties and the respective of coefficients determination $\left(R^{2}\right)$

\begin{tabular}{lcccc}
\hline & \multicolumn{4}{c}{$\begin{array}{c}\text { Coeficiente } \\
\text { Coefficient }\end{array}$} \\
\cline { 2 - 4 } $\begin{array}{l}\text { Variedade } \\
\text { Variety }\end{array}$ & $\mathrm{a}$ & $\mathrm{b}$ & $\mathrm{c}$ & $\mathrm{R}^{2}$ \\
\hline $\begin{array}{l}\text { Amarelo } \\
\text { Yellow }\end{array}$ & 58 & 35 & 0,06 & 0,98 \\
$\begin{array}{l}\text { Roxo } \\
\begin{array}{l}\text { Purple } \\
\text { Mistura }\end{array}\end{array}$ & 36 & 56 & 0,08 & 0,97 \\
$\begin{array}{l}\text { Mixture } \\
\text { Doce }\end{array}$ & 58 & 35 & 0,09 & 0,99 \\
Sweet & 45 & 43 & 0,06 & 0,98 \\
\hline
\end{tabular}

efetiva da PB, TEIXEIRA et al. (1996) obtiveram maior taxa 57,6\% para ração composta de milho e caroço de algodão moído, resultados esses inferiores ao do maracujá, cujos valores variaram de 68,89 a 80,83.

Para o teor de FDN, há certa semelhança com os resultados de TEIXEIRA et al. (1996), em que a maior degradabilidade foi $48,7 \%$ e a menor, $38,0 \%$. Observando-se os valores das degradabilidades efetivas da PB, pode-se inferir que a variedade amarela e a mistura apresentaram altos valores de "a" e "c" e baixo valor de "b"; conseqüentemente, essas variedades sofreram pouco a influência da taxa de passagem. A variedade roxa foi a que sofreu maior influência da taxa de passagem, pois apresentou "a" baixo e "b" alto, em relação às outras variedades. Pelos resultados obtidos para a degradabilidade efetiva da PB, pode-se afirmar que quase toda proteína disponível na casca (resíduo) de maracujá foi degradada no rúmen, ficando disponível para o crescimento microbiano, juntamente com a fração energética do resíduo.

\section{Taxa de passagem}

A taxa de passagem ruminal da fases sólida e líquida da digesta foi, respectivamente, 4,8 e $6,4 \% / \mathrm{h}$, quando os animais consumiram farelo de casca do fruto do maracujá. Pode-se observar pequena discrepância entre as duas taxas, mas não tão grande como a encontrada por GOMES (1991). Segundo esses autores, a determinação do consumo de água pelos animais evitaria essas discrepâncias, eliminando-se as coletas em que o marcador estivesse abaixo do esperado. $\mathrm{O}$ valor obtido para taxa de passagem de sólidos está próximo ao valor de 5\%, adaptado pelo 
1156 Rev. bras. zootec.

Tabela 8 - Estimativa dos coeficientes a, b e c das equações, ajustadas para degradabilidade potencial da fibra detergente neutro (FDN) dos resíduos (casca) das variedades de maracujá e respectivos coeficientes de determinação $\left(R^{2}\right)$

Table 8 - Estimate of $a, b$ and $c$ coefficients of the adjusted equations for potential degradabilities of neutral detergent fiber (FDN) of residues (shelves) of passion fruits varieties and the respectives coefficients of determination $\left(R^{2}\right)$

\begin{tabular}{lcccc}
\hline & \multicolumn{3}{c}{$\begin{array}{c}\text { Coeficiente } \\
\text { Coeficient }\end{array}$} \\
\cline { 2 - 4 } $\begin{array}{l}\text { Variedade } \\
\text { Variety }\end{array}$ & $\mathrm{a}$ & $\mathrm{b}$ & $\mathrm{c}$ & $\mathrm{R}^{2}$ \\
$\begin{array}{l}\text { Amarelo } \\
\begin{array}{l}\text { Yellow } \\
\text { Roxo }\end{array}\end{array}$ & 5 & 50 & 0,08 & 0,97 \\
$\begin{array}{l}\text { Purple } \\
\text { Mistura }\end{array}$ & 08 & 48 & 0,08 & 0,95 \\
$\begin{array}{l}\text { Mixture } \\
\begin{array}{l}\text { Doce } \\
\text { Sweet }\end{array}\end{array}$ & 02 & 58 & 0,09 & 0,97 \\
\hline
\end{tabular}

Agricultural Research Council - ARC (1984) para animais em regime de engorda.

\section{Consumo}

Na Tabela 10 encontra-se o consumo médio do farelo de casca (resíduo) de maracujá, com 90\% MS. Observa-se alto consumo médio diário de $16,90 \mathrm{~kg} /$ animal ou 156,11 g por unidade tamanho metabólico, o que representa consumo de $3,27 \%$ do peso vivo dos animais, refletindo a grande aceitação do material.

REIS (1994), trabalhando com silagens contendo 75, 50 e $25 \%$ de resíduos de fruto de maracujá, encontraram consumo de 58,$85 ; 60,46$; e $52,72 \mathrm{~g} / \mathrm{utm}^{-1} /$ dia, respectivamente. Neste estudo, os consumos de farelo de casca de maracujá foram bem maiores, provavelmente em função da ausência de ácidos orgânicos e nitrogênio não-protéico normalmente encontrados nas silagens.

$\mathrm{Na}$ Tabela 11 encontram-se os resultados relativos a pH e concentrações de $\mathrm{N}$-amoniacal e ácidos graxos volateis no líquido ruminal, durante o período de 24 horas, quando os animais estavam recebendo exclusivamente farelo da casca de maracujá. Não houve diferença nas concentrações de acetato, propionato, butirato e $\mathrm{N}$-amoniacal nos diferentes tempos de coleta, porém, o $\mathrm{pH}$ foi influenciado $(\mathrm{P}<0,05)$. Em relação aos ácidos graxos voláteis (AGV), observou-se grande diferença na relação: acetato - propionato - butirato, o que é normal atribuído ao alto teor de fibra do resíduo. O comportamento dos AGV totais é muito semelhante ao resultado encontrado por BERCHIELLI et al. (1996) e ESTEVES et al. (1987) e bastante inferior ao encontrado por FIGUEIRA (1991)
Tabela 9 - Degradabilidade efetiva dos resíduos (casca) das variedades de maracujá, para matéria seca (MS), proteína bruta (PB) e fibra em detergente neutro (FDN), para taxa de passagem $(\mathrm{k})$ de $4,8 \% / h$

Table 9 - Effective degradability of residues (shelves) of passion fruit varieties, for dry matter (MS), crude protein (PB) and neutral detergent fiber (FDN) at passage rate $(k)$ of $4.8 \% h$

\begin{tabular}{lccc}
\hline Variedade & MS & PB & FDN \\
Variety & $D M$ & $C P$ & $N D F$ \\
\hline Amarelo & 63,65 & 77,44 & 36,25 \\
$\begin{array}{l}\text { Yellow } \\
\text { Roxo }\end{array}$ & 63,46 & 71,00 & 40,00 \\
$\begin{array}{l}\text { Purple } \\
\text { Mistura }\end{array}$ & 63,46 & 80,83 & 45,83 \\
$\begin{array}{l}\text { Mixture } \\
\text { Doce }\end{array}$ & 63,46 & 68,89 & 34,61 \\
Sweet & & & \\
\hline
\end{tabular}

Quanto ao $\mathrm{N}-\mathrm{NH}_{3}$, as concentrações estiveram na faixa de 5 a $10 \mathrm{mg} / 100 \mathrm{~mL}$, mesmo às $24 \mathrm{~h}$, em que o animal estaria há bastante tempo sem se alimentar. Em todos horários, os níveis de amônia estiveram dentro do normal para o perfeito funcionamento do complexo ruminal. ROFFLER e SATTER (1975) observaram que o máximo de crescimento microbiano aconteceu com concentração máxima de $\mathrm{N}-\mathrm{NH}_{3}$ de $5 \mathrm{mg} / 100 \mathrm{~mL}$ do líquido ruminal. Assim como ADAMS e KARTCHNER (1984), verificou-se, neste experimento, pico máximo de $\mathrm{N}-\mathrm{NH}_{3}$ entre 2 e 4 horas após a alimentação.

$\mathrm{O} \mathrm{pH}$ do líquido ruminal apresentou comportamento quadrático, em função dos tempos de amostragem $(\mathrm{T})$, conforme a equação $\mathrm{pH}=6,385$ $0,089 \mathrm{~T}+0,004 \mathrm{~T}^{2}$. Foi observado que, apesar do alto consumo de farelo de casca de maracujá, em nenhum

Tabela 10 - Consumo de matéria seca do farelo da casca (resíduo) de maracujá, expresso em kg/ animal•dia, porcentagem de peso vivo (\%/PV) e gramas por unidade de tamanho metabólico (g/utm) e os respectivos pesos vivos dos animais

Table 10 - Dry matter intake of passion fruit shelves flower (residue), express as $\mathrm{kg} / \mathrm{animal} \bullet$ day, percentage of live weight (\%PV) and grams per metabolic size (g/utm) and respectives animal live weight

\begin{tabular}{|c|c|c|c|c|}
\hline \multirow{2}{*}{$\begin{array}{l}\text { Animal } \\
\text { № }\end{array}$} & \multicolumn{3}{|c|}{$\begin{array}{l}\text { Consumo } \\
\text { Intake }\end{array}$} & \multirow{2}{*}{$\begin{array}{c}\text { Peso vivo } \\
\text { Live weight } \\
\mathrm{kg}\end{array}$} \\
\hline & $\mathrm{kg} /$ Animal & $\% \mathrm{PV}$ & g.utm ${ }^{-1}$ & \\
\hline 1 & 16,77 & 3,29 & 156,49 & 509 \\
\hline 2 & 17,06 & 3,02 & 147,41 & 564 \\
\hline 3 & 16,86 & 3,51 & 164,42 & 480 \\
\hline $\begin{array}{l}\text { Média } \\
\text { Mean }\end{array}$ & 16,90 & 3,27 & 156,11 & 517,67 \\
\hline
\end{tabular}


VIEIRA et al.

Tabela 11 - pH e níveis de $\mathrm{N}$-amoniacal e ácidos graxos voláteis (AGV) no líquido ruminal de bovinos alimentados com farelo de casca (resíduo) de maracujá (Passiflora spp.), em diferentes tempos de coleta

Table 11 - $\quad \mathrm{pH}$ and levels of $\mathrm{N}$-amonium and volatile fatty acids (AGV) in ruminal liquid of cattle fed flower of shelves (residue) of passion fruit (Passiflora spp)

\begin{tabular}{lcccccc}
\hline $\begin{array}{l}\text { Tempo } \\
\text { de coleta }\end{array}$ & & $\begin{array}{c}\mathrm{NH}_{3} \\
\text { Sampling } \\
\text { time }\end{array}$ & $\mathrm{pH}$ & & \multicolumn{3}{c}{$\mathrm{AGV}(\mathrm{M}$ moles/100mL) } & \multirow{2}{*}{$\begin{array}{c}\text { Total } \\
\text { AGV }\end{array}$} \\
\cline { 4 - 6 } & & & $\begin{array}{c}\text { Acetato } \\
\text { Acetate }\end{array}$ & $\begin{array}{c}\text { Butirato } \\
\text { Butyrate }\end{array}$ & $\begin{array}{c}\text { Propionato } \\
\text { Propionate }\end{array}$ & \\
2 & 6,75 & 5,83 & 5,65 & 1,3 & 0,81 & 7,76 \\
4 & 6,34 & 9,86 & 7,26 & 1,85 & 1,12 & 10,23 \\
6 & 6,03 & 8,61 & 7,52 & 1,70 & 1,19 & 10,41 \\
8 & 6,21 & 7,06 & 6,83 & 1,50 & 1,01 & 9,34 \\
10 & 6,22 & 7,83 & 6,92 & 1,60 & 0,90 & 9,42 \\
24 & 6,11 & 5,71 & 8,12 & 1,50 & 0,97 & 10,59 \\
\hline
\end{tabular}

tempo após a alimentação o pH esteve abaixo de 6,0, o que, segundo HOOVER (1986), provocaria inibição drástica na digestão das fibras; no entanto, o ponto de mínima estimado às 11 horas indicou $\mathrm{pH}$ de 5,85.

\section{Conclusões}

Pode-se recomendar, por intermédio de análise bromatológica e comportamento na degradabilidade, no consumo e nas variáveis ruminais, a utilização do farelo da casca do maracujá como componente no balanceamento de rações para ruminantes.

As cascas (resíduos) das três variedades de maracujá estudadas possuem semelhança em vários aspectos nutricionais, podendo-se indicar qualquer uma para alimentação de ruminantes.

O alto teor de umidade da casca do fruto do maracujá pode limitar sua utilização na alimentação de bovinos.

\section{Referências Bibliográficas}

ADAMS, D.C., KARTCHNER, R.J. 1984. Effect of level of forage intake on rumen ammonia, $\mathrm{pH}$, liquid volume and liquid dilution rate in beef cattle. J. Anim. Sci., 58(3):708-713. AGRICULTURAL RESEARCH COUNCIL - ARC. 1984. Report of the protein group of the Agricultural Research Council Working party on the nutrient requirement of ruminants. London: Commonwealth Agricultural Bureaux. 45p.

ARIKI, J., TOLEDO, P.R., RUGGIERO, C. et al. 1977. Aproveitamento de cascas desidratadas e sementes de maracujá amarelo (Passiflora edulis f. Flavicarpa Deg.) na alimentação de frangos de corte. Científica, 3(3):340-343.

BERCHIELLI, T.T., RODRIGUES, N.M., ANDRADE, P. 1996. Concentração, proporção molar e taxa de produção de ácidos graxos voláteis (agv) no rúmen de bovinos alimentados com diferentes níveis de concentrado na dieta. R. Soc. Bras. Zootec., 25(3):511-521.

BURGI, R. Equipamentos para manejo e tratamento de resíduos agrícolas e agroindustriais. In: SIMPÓSIO SOBRE UTILI-
ZAÇÃO DE SUBPRODUTOS AGROINDUSTRIAIS E RESÍDUOS DE COLHEITA NA ALIMENTAÇÃO DE RUMINANTES, São Carlos, 1992. Anais... São Carlos: EMBRAPA, p.69-82, 1992.

DESCHAMPS, F.C. Avaliação de alimentos para ruminantes I. Desaparecimento da matéria seca (MS) da alfafa, palha de soja, aveia e palha de arroz, através da digestibilidade in situ. In: REUNIÃO ANUAL DA SOCIEDADE BRASILEIRA DE ZOOTECNIA, 28, João Pessoa, 1991. Anais... Viçosa: SBZ, 1991. p.183.

ESTEVES, S.N., MANZAMO, A., NOVAES, J. 1982. Substituição da espiga de milho desintegrada com palha e sabugo pela polpa de citrus peletizada na engorda de bovino Canchin. R. Soc. Bras. Zootec., 16(6):507-516.

FIGUEIRA, D.G. Efeito do nível de uréia sobre a digestibilidade aparente e "in situ" e a dinâmica da fase sólida em bovinos alimentados com cana-de-açúcar e farelo da algodão. Belo Horizonte: UFMG, 1991. 123p. Dissertação (Mestrado em Zootecnia) - Universidade Federal de Minas Gerais, 1991.

GOMES, B.V. Influência das características químicas e físicas das forragens sobre o consumo, degradação e cinética da digesta ruminal. Viçosa: UFV, 1991. 115p. Tese (Doutorado em Zootecnia) - Universidade Federal de Viçosa, 1991.

HOOVER, W.H. 1986. Chemical factors involved in ruminal fiber digestion. J. Dairy Sci., 69(10):2755-2766.

KÖEPPEN, W. 1948. Climatologia. Buenos Aires: Panamericana. 478p.

MANTEROLA, H.B., DURA CERDA, A., PORTE, E. F. et al. Valor nutritivo y uso de resíduos hortifrutícolas y agroindustriales en alimentacion de ruminantes. In: SIMPÓSIO SOBRE UTILIZAÇÃO DE SUBPRODUTOS AGROINDUSTRIAIS E RESÍDUOS DE COLHEITA NA ALIMENTAÇÃO DE RUMINANTES, São Carlos, 1992. Anais... São Carlos: EMBRAPA, p.297-324, 1992.

MEHREZ, A.Z., ORSKOV, E.R. 1977. A study of the artificial fibre bag technique for determining the digestibility of feeds in the rumen. J. Agric. Sci., 88:645-665.

NOCEK, J.E. 1988. "In situ" and other methods to estimate ruminal protein and energy digestibility. A review. J. Dairy Sci., 71:2051-2069.

OLIVEIRA, J.C. de. Melhoramento genético de Passiflora edulis Sim Flavicarpa Deg. visando aumento de produtividade. Jaboticabal: UNESP, 1980. p.133. Tese (Livre Docência) Universidade Estadual de São Paulo, 1980. 
1158 Rev. bras. zootec.

ORSKOV, E.R., Mc DONALD, I. 1979. The estimation of protein degradability in the rumen from incubation measurements weighted accordin to rate of passage. J. Agric. Sci., 92(4):499-503.

OTAGAKI, K.K., MATSUMOTO, H. 1958. Nutritive values and utility of passion fruit by products. J. Agr. Food Chem., 6:54-56.

PRUTHI, S., CHISCHESTER, C.O., MAK, E.M. et al. 1963. Physiology, chemistry and technology of passion fruit. In: Advances in food research. New York: Academic Press, v.12. p.203-282.

REIS, J. Composição química, consumo voluntário e digestibilidade das silagens de resíduo do fruto de maracujá (Passiflora edulis, Sims f. flavicarpa) com capim-elefante (Pennisetum purpureum, Schum), cv cameroon e suas combinações. Lavras: UFLA, 1994. 50p. Dissertação (Mestrado em Zootecnia) - Universidade Federal de lavras, 1994.

ROFFLER, R.E., SATTER, L.D. 1975. Relationship between ruminal ammonia and nonprotein utilization by ruminants. I Develloppment of a model for predicting nonprotein nitrogen utilization by cattle. J. Dairy Sci., 58(12):1880-1888.

SAS - Statiscal Analisys System. 1990. User's guide. SAS Institue Inc. Cary, NC. 142p.

SILVA, D.J. 1990. Análise de alimentos (métodos químicos e biológicos). 2 ed. Viçosa: UFV. 165p.

TEIXEIRA, J.C., SANTOS, R.M. dos, OLIVEIRA, A.I.G. 1996. Degradabilidade ruminal de matéria seca, proteína bruta e fibra em detergente neutro de rações contendo caroço algodão e grão de milho em diferentes formas físicas, em vacas de raça holandesa. R. Soc. Bras. Zootec., 25(4):814-823.
UDEN, P., COLUCCI, P.E., VAN SOEST, P.J. 1980. Investigation of chromium, cerium and cobalt as markers in digesta. Rate of passage studies. J. Sci. Food Agric., 31:625-632.

VILELA, G.L. Degradabilidade in situ da matéria seca e da proteína bruta de vários alimentos em vacas alimentadas com diferentes rações. Viçosa: UFV, 1994. 68p. Dissertação (Mestrado em Zootecnia) - Universidade Federal de Viçosa, 1994.

WILSON, R.K. 1971. A rapid accurate method for measuring volatile fatty acids and latic acid in silage. Dimsinea: Research Report Agricultural Institute. 30p.

ZAGATTO, L.C.A.G. Impactos sócio-econômicos da utilização de resíduos da agro-indústria e beneficiamento de produtos agrícolas na alimentação de ruminantes. In: SIMPÓSIO SOBRE UTILIZAÇÃO DE SUBPRODUTOS AGROINDUSTRIAIS E RESÍDUOS DE COLHEITA NA ALIMENTAÇÃO DE RUMINANTES, São Carlos, 1992. Anais... São Carlos: EMBRAPA, p.29-44, 1992.

Recebido em: 20/03/98

Aceito em: 08/03/99 